\title{
On Leishmania enriettii and Other Enigmatic Leishmania Species of the Neotropics
}

\author{
Ralph Lainson
}

Departamento de Parasitologia, Instituto Evandro Chagas, Caixa Postal 691, 66017-970 Belém, PA, Brasil

There are 20 named species of the genus Leishmania at present recognized in the New World, of which 14 are known to infect man. The present paper discusses the biological, biochemical and ecological features, where known, of six species which have not till now been found to cause human leishmaniasis; namely, Leishmania (Leishmania) enriettii, L. (L.) hertigi, L. (L.) deanei, L. (L.) aristidesi, L. (L.) forattinii and L. (Viannia) equatorensis. A protocol is suggested for attempts to discover the natural mammalian host(s) and sandfly vector of L. (L.) enriettii. Doubt is cast on the validity of the species $\mathrm{L}$. herreri, described in Costa Rican sloths. Following the concensus of opinion that modern trypanosomatids derive from monogenetic intestinal flagellates of arthropods, phlebotomine sandflies are best regarded as the primary hosts of Leishmania species, with mammals acting as secondary hosts providing a source of parasites for these insects. There are probably natural barriers limiting the life-cycle of most leishmanial parasites to specific sandfly vectors.

Key words: neotropical Leishmania - Leishmania (Leishmania) enriettii - Leishmania (Leishmania) hertigi Leishmania (Leishmania) deanei - Leishmania (Leishmania) aristidesi - Leishmania (Leishmania) forattinii Leishmania (Viannia) equatorensis - Leishmania herreri

Up until the 1940's, all the recognized species or "varieties" of Leishmania were better known as causative agents of human leishmaniasis and, apart from the role of the domestic dog, Canis familiaris, as a reservoir of visceral leishmaniasis due to $L$. (L.) infantum and L.(L.) chagasi in the Old World and the New World, respectively, and rodents as the major reservoir of $L .(L$. $)$ major in Turkmenia, almost nothing was known about Leishmania species infecting other mammals until Medina (1946) recorded natural infections of domestic guinea-pigs (Cavia porcellus) with a strange new Leishmania species in the State of Paraná, Brazil.

The discovery of this parasite, named $L$. (L.) enriettii by Muniz and Medina (1948), was something of a mile-stone in the history of Leishmania and leishmaniasis. The exuberant growth of its large amastigotes in the skin of the guinea-pig, and the ease with which the parasite is grown in simple blood-agar media, soon made the parasite a favourite model for immunologists, biochemists and molecular biologists throughout the world, and a popular subject for chemotherapeutic studies. Equally important, however, was that its discovery greatly strengthened the growing belief that not only might there be a multiplicity of different Leishmania species in wild or domestic animals, but that

Fax: +55-91-223.2382

Received 5 August 1996

Accepted 31 October 1996 the great majority of the human leishmaniases were zoonoses, with different animals acting as specific sources of the Leishmania species responsible for each of these human diseases.

Intensifying ecological and epidemiological studies, particularly in the Americas, subsequently showed both speculations to be correct. Thus, workers at the Gorgas Memorial Laboratories in Panama isolated a Leishmania species from the "spiny rats" Hoplomys gymnurus and Proechimys semispinosus, after culture of their blood in NNN medium (Anon 1957, 1959). Forattini (1960), working with wild animals in the State of São Paulo, Brazil, found amastigotes in the skin lesions of an agouti, Dasyprocta azarae, and another rodent, Kannabateomys amblyonyx, and grew promastigotes in blood-agar culture of the blood from yet another rodent, Agouti paca. Unfortunately, none of these leishmanial parasites was identified.

Concrete evidence that wild animals acted as the reservoir of a neotropical Leishmania species already known to commonly infect man was first provided by Lainson and Strangways-Dixon (1962, 1964). Working in primary forest in Belize, they incriminated the rodents Ototylomys phyllotis, Heteromys desmarestianus and Nyctomys sumichrasti as natural hosts of $L$.(L.) mexicana, the causative agent of "chiclero's ulcer". The finding stimulated similar eco-epidemiological studies in other parts of Latin America, particularly Brazil, and culminated in the present recognition of no 
less than 20 named species of neotropical Leishmania, 14 of which* are known to infect man.

\section{Species of Leishmania at present recognized in Latin America}

Subgenus Leishmania Saf'janova, 1982

Leishmania (Leishmania) chagasi Cunha \& Chagas, 1937*

L. (L.) enriettii Muniz \& Medina, 1948

L. (L.) mexicana Biagi, 1953 emend Garnham, 1962*

L. (L.) pifanoi Medina \& Romero, 1959 emend Medina \& Romero, 1962*

L. (L.) hertigi Herrer, 1971

L. (L.) amazonensis Lainson \& Shaw, 1972*

L. (L.) deanei Lainson \& Shaw, 1977

L. (L.) aristidesi Lainson \& Shaw, 1979

L. (L.) garnhami Scorza et al., 1979*

L. (L.) venezuelensis Bonfante-Garrido, 1980*

L. (L.) forattinii Yoshida et al., 1993

Subgenus Viannia Lainson \& Shaw, 1987

Leishmania (Viannia) braziliensis Vianna,

1911 emend Matta, 1916* (TYPE SPECIES of the Subgenus)

L. (V.) peruviana Velez, 1913*

L.(V.) guyanensis Floch, 1954*

L. (V.) panamensis Lainson \& Shaw, 1972*

L. (V.) lainsoni Silveira et al., 1987*

L. (V.) shawi Lainson et al., 1989*

L. (V.) naiffi Lainson \& Shaw, 1989*

L. (V.) colombiensis Kreutzer et al., 1991

L. (V.) equatorensis Grimaldi et al., 1992

The eco-epidemiology of the neotropical leishmanial pathogens of man has been dealt with at length in previous publications (Lainson \& Shaw 1979, 1987, Lainson 1982a,b, 1983, Shaw \& Lainson 1987, Grimaldi et al. 1989, Kreutzer et al.1991, Lainson et al. 1994). Here it is proposed to discuss some of the Leishmania species that have not, till now, been found in man, or of which the validity remains in doubt.

\section{LEISHMANIA (LEISHMANIA) ENRIETTII}

Phlebotomine sandflies are the only known vectors of Leishmania species, and it is difficult to imagine, therefore, that domestic guinea-pigs are the principal natural hosts of $L$.(L.) enriettii. The previous history of Professor Medina's infected animals was obscure and gave no clues as to the source of their infection. It can only be assumed that they spent some time in or near a rural area where transmission of $L$. (L.) enriettii was going on among the true, wild animal hosts; although what this natural host is remains a mystery till now.

Muniz and Medina (1948) were apparently unable to experimentally infect mice, wild guinea- pigs (Cavia aperea), dogs, rhesus monkeys or human volunteers, and the inoculation of eight hamsters resulted in a small skin lesion containing scanty amastigotes in only one of these animals. At first sight this suggests $L$.(L.) enriettii to be a parasite with considerable host specificity, and that the natural host might be a member of the Order Rodentia. Failure to produce a visible skin lesion in inoculated animals, however, is no sure indication that those animals are completely unsusceptible to infection with a given parasite. Thus, the inoculation of L. (Viannia) naiffi of the armadillo Dasypus novemcinctus into the skin of the hamster very rarely produces a visible skin lesion, but the parasite may be retrieved from apparently normal skin at the site of the inoculation, a year or more later, by its culture in blood-agar medium. Infections of L. (L.) amazonensis in the wild rodent and marsupial hosts are almost always inapparent, in what appears to be perfectly normal skin. Such occult skin infections have been recorded for $L$. $(L$.) tropica in man, with leishmanial skin lesions appearing at the site of cuts or abrasions many years after persons have left the endemic areas of this parasite. With this in mind, the failure of Muniz and Medina to produce skin lesions in the wild guinea-pig, Cavia aperea, with a parasite which produces large, metastasising lesions in the skin of the closely related domestic species, Cavia porcellus, might not be so strange as it would first appear. There is, perhaps, a parallel example in the behaviour of L.(L.) amazonensis, which produces huge, metastasising skin lesions in the hamster, a member of the family Cricetidae, but only a benign, inapparent infection in the skin of its natural, wild cricetid hosts.

In 1967, Luz et al., recorded the reappearance of spontaneous guinea-pig leishmaniasis due to $L$. (L.) enriettii in the outskirts of Curitiba, State of Paraná, and studied the sandfly population of neighbouring forest, where the native pine-tree (Araucaria angustifolia) predominated. Lutzomyia monticola (Costa Lima) and Lu. correalimai Martins, Coutinho \& Luz were the only species encountered, with $\mathrm{Lu}$. monticola being taken from the "nests" of opossums (Didelphis) in trees, on tree-trunks, and from human bait, during the warmer part of the year. Ten specimens of Lu. monticola were fed on the lesions of an infected guinea-pig. Although six of them developed heavy promastigote infections, the flagellates apparently failed to produce an infection when inoculated into the skin of a clean laboratory guineapig, and the second chapter in the history of $L$. $(L$. enriettii was to close with the parasite still shrouded in mystery. 
Twenty-two years were to elapse until naturally infected guinea-pigs were seen again, this time in the neighbouring State of São Paulo (SP). A family from the metropolitan area of Mogi das Cruzes, close to the city of São Paulo, acquired two domestic guinea-pigs from the municipal market of Pinheiros, SP. The animals appeared to be perfectly healthy and, seven months later, were taken by the family to a countryside farm in Capão Bonito, relatively close to remnants of the Atlantic Forest. Some time later, both animals developed ulcerating nodules on their ears and were taken to the Institute of Biomedical Sciences, SP, for examination. The presence of large numbers of big amastigotes, in Giemsa-stained smears made from the lesions, left little doubt as to the nature of the causative parasite, and subsequent study of its isoenzyme profiles and further passage into laboratory guinea-pigs, soon confirmed that the mysterious $L$. $(L$.) enriettii had once again appeared out of the blue (Machado et al. 1994). With an area of active transmission of the parasite pinpointed with such precision, it is a great pity that field studies were not started at once, and now, some six years later, there may well have been landscape changes in the immediate locality. However, it should be possible to select some ecologically comparable areas in the near vicinity where one might, for once and for all, clear up the 49 year-old mystery of the wild animal host and sandfly vector of $L$. (L.) enriettii. The modus operandi should, ideally, include the following:

Selection of the study area - There is no point in starting field-work if a reliable guarantee cannot be given that the selected area will remain unmolested during the estimated period of study preferably for two or three years. The nature of the research should be explained to the local governmental authorities, land owners, etc., to gain such an assurance.

Working facilities - It is usually impractical for a laboratory to maintain a continuous field programme throughout the year, unless the study area is nearby, but attempts should be made to see that separated field-trips do, at least, cover periods of conspicuous seasonal change - such as dry and wet seasons. The phlebotomine sandfly fauna will certainly vary considerably during different climatic conditions, and the abundance of certain mammalian species may also be affected.

When possible, it is best to send both trapped mammals and sandflies back to the home-based laboratory, where conditions are more favourable for their examination under sterile conditions. Failing this, both must be dealt with in the field, and an improvised laboratory set up. A chat with the mayor, hospital or medical post supervisor, or the local school-teacher will usually work wonders, and may result in the provision of a refrigerator and other commodities into the bargain. Once set up, the room will need fairly ample table space and electric points from which to operate microscopes, etc. If it is possible to instal some sort of sterile cabinet (the lamina-flow type, equipped with ultraviolet light is ideal), cultures can be made from both animal tissues and any flagellates found in dissected sandflies. If not, it is best to rely solely on the intradermal inoculation of such material into the skin of laboratory animals brought to the field for such purpose. In a search for natural hosts of L.(L.) enriettii, these will, of course, be laboratory guinea-pigs and, in view of the past encounter of the parasite in guinea-pigs of uncertain origin, extreme care will be needed to ensure that these animals are from a laboratory-bred colony which is out of the range of any possible sandfly transmission.

Examination of trapped animals - The carcases of small animals should be washed with soap and water and then well rinsed under a running tap. In the sterile cabinet, the whole work-area should be well swabbed down with $70 \%$ alcohol or, if the cabinet has an ultraviolet lamp this should have been switched on some hours previously (overnight). Areas of naked skin of the animal, such as the ears, nose or tail, are rigorously cleaned with $70 \%$ alcohol containing iodine, again with pure $70 \%$ spirit, to remove every trace of the iodine, and then with sterile physiological saline $(0.85 \%)$.

Snips of skin from the cleaned areas are pooled in a small quantity of sterile saline and ground with a pestle and morter: the addition of a tiny quantity of fine, sterile sand greatly facilitates trituration. If sterile precautions have been well carried out, the use of antibiotics should be unnecessary and, in fact, are undesirable, as there is some evidence that their use is detrimental to the growth of some Leishmania species. Some workers nevertheless prefer to use approximately 200 IU penicillin and $2.0 \mathrm{mg}$ streptomycin per $\mathrm{ml}$ of saline. A similar triturate should then be prepared from a pool of liver and spleen tissue from the same animal. The skin and viscera suspensions can be used for both culture in diphasic blood-agar media (see below) and the inoculation of the laboratory animals.

Intradermal inoculation of the triturated tissues may be made into the skin of the nose, ears and feet of the laboratory animals, which should be protected against any possible bites of sandflies, returned to the home-based laboratory as soon as possible and periodically examined for the appearance of any cutaneous lesions at the sites of the inoculations. 
Impression smears of skin, liver and spleen of each wild animal can be prepared and stained by the usual Giemsa method. In the author's experience, however, the chances of detecting amastigotes in animals with natural, inapparent infections of most species of Leishmania are remote.

Examination of phlebotomine sandflies - The occurrence of natural infections in the domestic guinea-pig suggests these animals to be attractive to the vector of this parasite. Disney-traps, Shannon-traps and CDC miniature light traps (Figs 13 ) baited with this animal can be operated at night, in suitable localities. The use of wild guinea-pigs (preá) associated with such traps might give particularly interesting results.

The baited Disney-traps (Disney 1966) should be set at dusk, usually at ground level, and the oiled trays brought back to the field laboratory early the next morning. Any sandflies caught are removed, washed in physiological saline containing a drop of detergent to remove the oil and most of the insect hairs, and passed through two or three washes in pure saline. They may be kept in a small vial in the $4^{\circ} \mathrm{C}$ compartment of a refrigerator, but the sooner they are dissected for the detection of flagellates the better.

If it is intended to culture detected flagellates, scrupulously clean, sterile slides and cover-slips should have been prepared, together with sterilized dissecting needles, and forceps to manipulate the cover-slips. A supply of sterile $1.0 \mathrm{ml}$ syringes with needles should also be to hand, a vial of sterile $0.85 \%$ saline containing $0.5 \% 5$-fluorocytocine ("Alcobon") and penicillin 200 IU plus streptomycin $2.0 \mathrm{mg}$ per $\mathrm{ml}$, to avoid fungal and bacterial contamination, a gas Bunsen-burner and a number of tubes of diphasic blood-agar culture medium (e.g. NNN) closed by rubber vaccine stoppers.

It is best if the team of workers is divided into two groups: one or more persons to dissect out the sandfly guts, and the others to examine them for flagellates. Each female fly is dissected in a small drop of the saline containing the anti-fungus and antibiotics and the gut covered with a small coverslip. Care should be taken to ensure that the terminal segments of the abdomen, containing the spermathecae, are included in the preparation, for identification of the sandfly species. Three or four such dissections can be made on a single slide, providing the cover-slips are small enough.

The dissected sandfly guts are best examined under phase-contrast illumination or, failing this, with the microscope condensor racked well down. Flagellates can usually be detected under the low power objectives (Fig. 4), and their distribution in the intestine should be carefully noted, as this is of
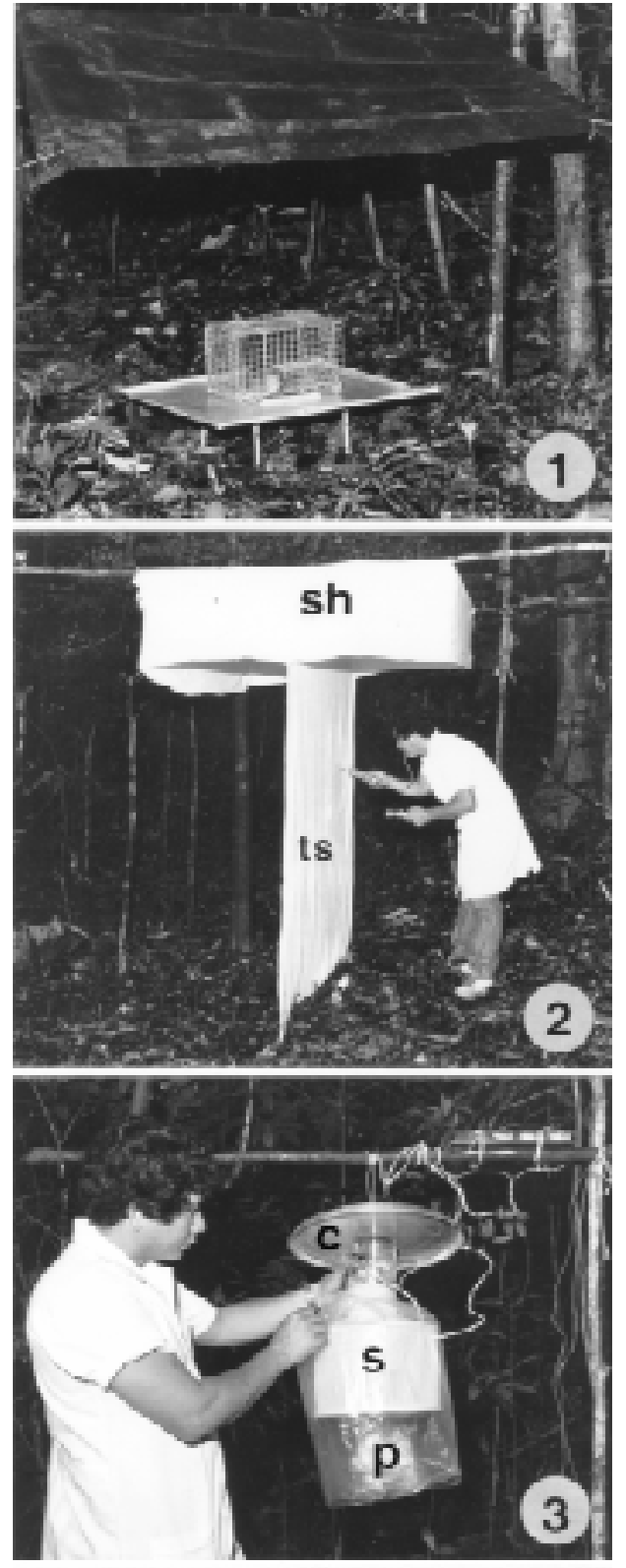

Fig. 1: a simplified Disney-trap. An aluminium tray coated with castor-oil is supported on wooden sticks about eight inches above the forest floor, and a cage containing the rodent bait is placed in its centre. Plastic sheeting protects the trap from rain. Fig. 2: the Shannon-trap (sh) is made from white cloth sheets and suspended so that the trailing sheet (ts) just reaches the forest floor. Light from a fluorescent lamp placed on the ground may be the sole attractant for sandflies, which are collected with an aspirator from the sheeting. Caged animals may be used as additional bait, while the collector will attract anthropophilic species. Fig. 3: a CDC miniature light-trap, driven by torch batteries, is suspended at a convenient distance from the forest floor. If placed immediately above an animal bait it will catch sandflies coming to that bait, in addition to those attracted by the light source. The metal and plastic covers ( $c$ and p) protect the trap and the cage of captured sandflies (s) from rain. 
considerable importance in the basic taxonomy of leishmanial parasites. It must be remembered that phlebotomine sandflies are commonly infected with the developmental stages of trypanosomes and some practise is required in distinguishing these from the promastigotes of a Leishmania.

On finding a flagellate infection, the first step is to remove the cover-slip, after introducing a little more sterile saline from a syringe. Great care must be taken not to lose the spermathecae, which must be preserved in a suitable mountant on another slide for future reference. If the intestine is still intact, it must be teased apart with the sterile needles, to release the contained flagellates which are taken up into a syringe already containing from $0.2-0.3 \mathrm{ml}$ of the treated saline. After swabbing the rubber caps of the culture tubes with $70 \%$ spirit, one or two drops of the flagellate suspension are injected through the caps into each of two tubes, and the remainder can be used to inoculate guinea-pigs. If conditions preclude culture, all the flagellate suspension must be inoculated into laboratory animals. Even if the object of the investigation is to isolate $L$. (L.) enriettii, it is advisable to inoculate both guinea-pigs and hamsters. Other species of Leishmania may be encountered which do not readily infect the guinea-pig. Finally, it is useful to dry the slide on which the infected fly was dissected, carefully mark the area with a diamond pencil, fix it in absolute methyl alcohol and stain with Giemsa. Usually some flagellates will have remained on the slide. Once an infected sandfly is found, it will clearly be advisable to concentrate the mammal and sandfly captures in the area in which it was caught.

The morphology of the amastigotes of $L$. (L.) enriettii and their exuberant growth in the skin of the laboratory guinea-pig will leave little doubt as to the nature of any isolations. Final confirmation, however, should be sought by the conventional use of enzyme profiles (Machado et al. 1994), monoclonal antibodies or DNA techniques.

\section{LEISHMANIA (LEISHMANIA) HERTIGI}

This parasite was first described in the Panamanian porcupine, Coendou rothschildi Thomas, by Herrer (1971), and more recently in porcupines from Costa Rica. Till now, it has been found in no other mammalian species.

Herrer found $88 \%$ of the porcupines he examined to be infected. The infections were all asymptomatic, with small numbers of amastigotes scattered in the dermis and viscera, where they provoked no host-cell reaction. The organism grows well in simple blood-agar culture medium, but very poorly in the skin of the hamster, in which the infection soon dies out. In both the porcupine and transitory infections of hamsters, the amastigotes were described as peculiarly elongated bodies measuring from $3.5 \times 1.2$ to $4.8 \times 2.5 \mu \mathrm{m}$. The vector of the parasite is till now unknown.

\section{LEISHMANIA (LEISHMANIA) DEANEI}

In 1974, the late Leonidas Deane and colleagues recorded the presence of scanty, large amastigotes in spleen and liver smears of porcupines suspected to be Coendou p. prehensilis (Fig. 5) from forest in the municipality of José de Freitas, State of Piauí, Brazil. The parasite was not isolated and, in view of the scanty material, it was given no name. Lainson and Shaw (1977) examined 18 porcupines from forest in the State of Pará, Brazil, and isolated flagellates in blood-agar cultures of skin and viscera from 11 of them. Two of the animals were C. $p$. prehensilis, and all the others were of a previously undescribed species of Coendou. All the infections were of an inapparent nature.

Smears of the liver and spleen of one animal revealed scanty, large amastigotes (Fig. 6). They measured from $5.1 \times 3.1$ to 6.8 x $4.5 \mu \mathrm{m}$, average 6.1 x $3.7 \mu \mathrm{m}$, and possessed a highly vacuolated cytoplasm containing a densely staining nucleus and a kinetoplast in the form of a small curved rod. Histological sections showed the organism to be scattered, usually singly, in the dermis (Fig. 7) and the viscera. Like $L$. (L.) hertigi, it was found to produce only a transient infection in the skin of the hamster, and no infection at all in the guineapig. Curiously, the authors were unable to determine the exact location of the parasites in the infected tissues of the infected porcupines, "....for all the amastigotes seen in smears were extracellular and no clear association of parasite and host cell was apparent in sections".

The measurements and other morphological features of the parasite were exactly those given by Deane et al. for the amastigotes they found in the porcupines from Piauí, and there is no doubt that they were dealing with the same parasite. In view of its morphology, biochemistry and other peculiarities it was given the subspecific name of Leishmania hertigi deanei Lainson \& Shaw 1977, and was later raised to the specific rank of $L$. (L.) deanei (Lainson \& Shaw 1987). To date this strange parasite has not been found in any mammalian host other than Coendou species, and its vector remains unknown. Till now, its amastigotes are larger than all those of the known Leishmania species (Figs $6,8)$.

It would appear that these two parasites of neotropical porcupines are highly host-specific, and it is likely that each has an equally host-specific vector. From the arboreal habits of Coendou species it is most probable that the vectors are com- 

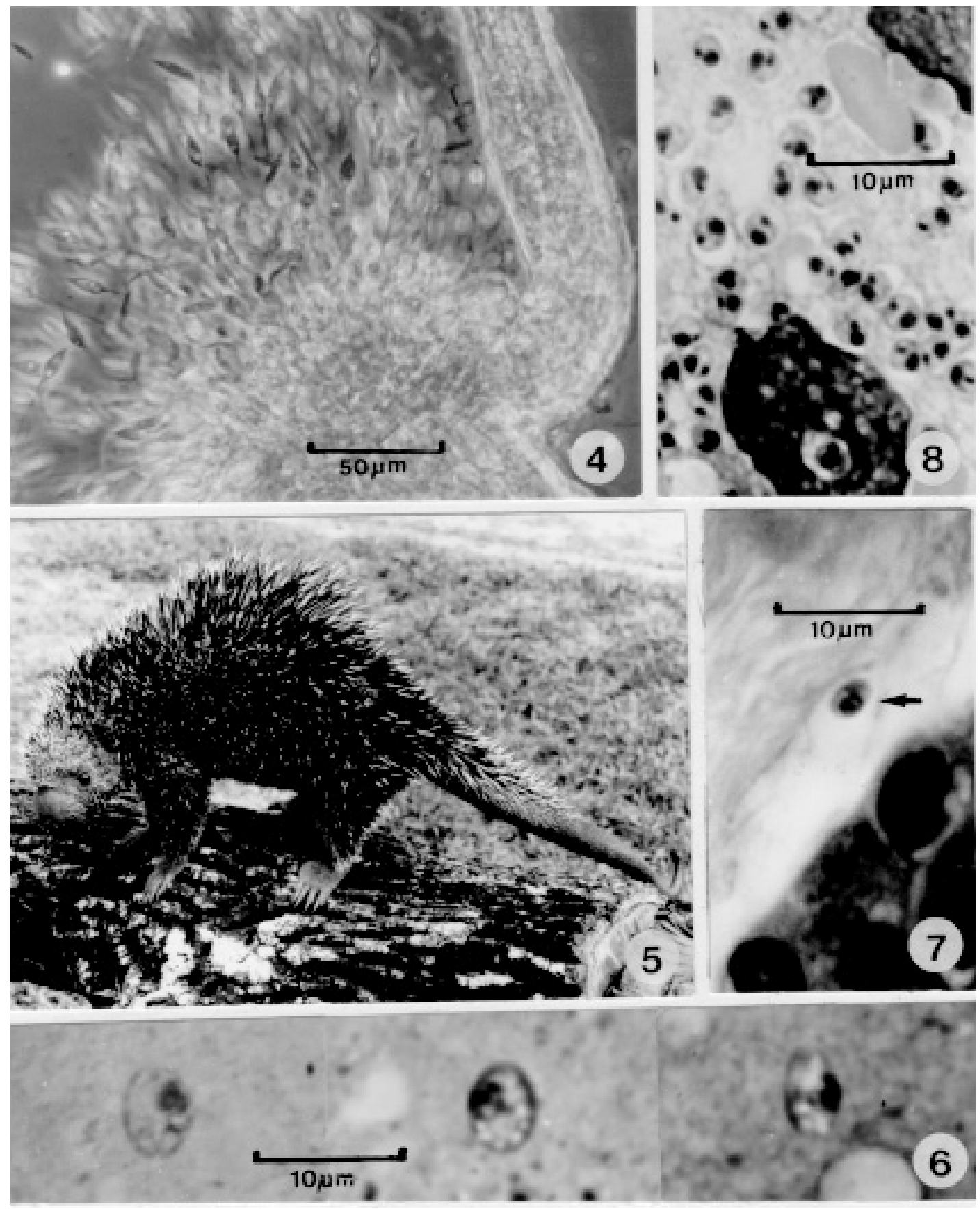

Fig. 4: ruptured, anterior part of a sandfly gut naturally infected with promastigotes of Leishmania. Large number of flagellates are seen exuding from the broken end of the intestine. Fresh preparation, phase-contrast microscopy. Fig. 5: the tree-porcupine, Coendou p. prehensilis, host of Leishmania (L.) deanei. From Lainson, 1982a. Fig. 6: extracellular amastigotes of Leishmania $(L$.$) deanei in a Giemsa-stained smear of liver from Coendou p. prehensilis. Note the highly vacuolated cyto-$ plasm, and compare the size of the amastigotes with that of Leishmania $(L$.) chagasi (Fig. 8) seen at the same magnification. From Lainson and Shaw (1977). Fig. 7: a histological section of the skin of a porcupine infected with Leishmania (L.) deanei, showing a single amastigote (arrowed) which appears to be extracellular. The parasites evoke no host-cell reaction. From Lainson and Shaw (1977). Fig. 8: amastigotes of Leishmania (L.) chagasi, the causal agent of American visceral leishmaniasis, in a Giemsa-stained smear of spleen from an infected dog. 
monly found on large tree-trunks, or in even closer association with porcupines in their homes in hollow trees. Miles et al. (1980) recorded the isolation of $L$. (L.) deanei from a sandfly, Lutzomyia furcata, caught in a hollow tree in which an infected porcupine was living. In experimentally infected $L u$. furcata, however, promastigotes persisted in the midgut only up to the digestion of the bloodmeal and were then eliminated (Lainson \& Shaw 1987).

Both $L$. (L.) hertigi and $L .(L$.$) deanei are very$ widely separated from all the known species of Leishmania in terms of their molecular biology and biochemistry. Thus, the nDNA buoyant density figure of $1.715 \mathrm{~g} / \mathrm{ml}$ (Croft et al.1978) is exceptional and, in fact, closest to some non-leishmanial haemoflagellates of lizards, such as Sauroleishmania adleri and S. hoogstraali (1.716 $\mathrm{g} / \mathrm{ml}$ ). On isoenzyme profiles (Miles et al. 1980), at least 11 enzymes (ASAT, ALAT, PGM, GPI, G6PDH, MDH, PEP, PK, PGK2.7.2.3., MPI and ACP3.1.3.2) separate the porcupine parasites from the other common Amazonian member of the subgenus Leishmania, L. (L.) amazonensis, and Cupolillo et al. (1994) also indicated the parasite to be widely separated from all known members of the mexicana complex, based on numerical zymotaxonomy. On the existing biological and biochemical criteria, one indeed wonders if these peculiar kinetoplastids of neotropical porcupines should be included in the genus Leishmania!

$L$. (L.) hertigi and $L$. (L.) deanei can be separated serologically by the Noguchi-Adler test (Croft et al. 1978), and on enzyme profiles for ME and MPI (Miles et al. 1980) and GPI and G6PDH (Croft et al. 1978).

Working with 12 isolates of $L .(L$.$) deanei from$ Pará, Miles et al. (1980) found that these were separable into two sub-groups, (a) and (b), containing 5 and 7 isolates respectively, by the three enzymes ME, PGM and MDH. There was, however, no apparent relationship of the two zymodemes to the two different species of Coendou from which they had been isolated, or to geographical distribution (the two groups were sympatric). These authors considered the isolates in sub-group (b) to represent $L$. (L.) deanei sensu stricto Lainson \& Shaw (1977), as it was with material from these isolates that the parasite was first described. In their classification of the Leishmania species, the latter authors (1987) placed $L$. (L.) hertigi and $L$. (L.) deanei in "The Leishmania (L.) hertigi complex". It may well be necessary to give a new specific name to the parasite of sub-group (a), within the complex, but only after a further examination of its morphology, biochemistry and molecular biology and a careful comparison of these characters with those of $L$. (L.) hertigi and $L$. (L.) deanei sensu stricto.

\section{LEISHMANIA (LEISHMANIA) ARISTIDESI}

Herrer (1971) isolated this parasite from the rodents Proechimys semispinosus, Oryzomys capito and Agouti paca, and the marsupial Marmosa robinsoni in the Sasardi forest, San Blas Territory, Eastern Panama. Which of these animals represents the major host-reservoir species is uncertain. Superficially it appeared to be Oryzomys, with 14 out of $39(36 \%)$ of these animals positive, but the infection in this rodent was characterized by destructive skin lesions which do not suggest a good host-parasite relationship. On the other hand, only 8 out of 202 (4\%) of the Proechimys yielded parasites, but at least 4 of them had completely inapparent infections, and in the other 4 ear damage may have been due to mechanical trauma. The single infected Marmosa, out of 35 specimens examined, had a conspicuous skin lesion, while 1 out of 2 pacas had an inapparent skin infection.

The sandfly species most suspected as the vector of L. (L.) aristidesi is Lu. olmeca bicolor. Christensen et al. (1972) found it to be the dominant fly on Disney-traps baited with Oryzomys, Proechimys and the opossum Metachirus in the area where infected animals had been captured, and that it was the most common species collected among leaf-litter on the forest floor.

Although no human infection with $L$. (L.) aristidesi has been reported to date, the suspected vector, Lu. olmeca bicolor, does bite man on rare occasions, and it remains likely that the parasite may eventually be found infecting him. In this respect it might be remembered that following the discovery of $L$. (V.) naiffi in armadillos (Lainson et al. 1979), 11 years were to elapse before concrete evidence was found to indicate the parasite as a cause of human cutaneous leishmaniasis (Naiff et al. 1989, Lainson et al. 1990)

\section{LEISHMANIA (LEISHMANIA) FORATTINII}

In 1979, Yoshida et al., published a preliminary note recording the isolation of a Leishmania species from pooled liver and spleen of an opossum, Didelphis marsupialis aurita, captured in forest in Conchas, SP, Brazil and, in a later communication (Yoshida et al. 1985), considered the parasite to be a member of the L. mexicana complex.

Barretto et al. (1985) made an isolation of a similar parasite from the skin of a single specimen of the rodent Proechimys iheringi denigratus caught in forest in the municipality of Três Braços, State of Bahia, Brazil, and again referred to it as $L$. mexicana. 
In a later comparison of the two isolates with other species of Leishmania using biological, biochemical and molecular criteria, it was concluded that they were of a previously undescribed parasite, which received the name of $L$. (L.) forattinii, and was considered to be most closely related to $L$. (L.) aristidesi (Yoshida et al. 1993). This relationship was again indicated by Cupolillo et al. (1994) who, in a paper on the numerical zymotaxonomy of neotropical Leishmania species, stated that the two isolates of the parasite ".....were classified in a zymodeme.......related to L. aristidesi in the cladistic analysis, as well as by other data using monoclonal antibodies".

The sandfly vector of $L$. (L.) forattinii remains to be identified, although Barretto et al. (1985) found the parasite to develop throughout the intestine of experimentally infected Psychodopygus ayrozai and Lutzomyia yuilli from the Três Braços area, where these two sandflies are very abundant. Both of these insects occasionally feed on man and, although no human infections with $L$. (L.) forattinii have yet been registered, they may well occur if one or other of these sandflies is indeed the vector.

\section{LEISHMANIA (VIANNIA) EQUATORENSIS}

During ecological and epidemiological studies on human leishmaniasis in Ecuador, flagellates were isolated in Schneider's Drossophila medium (Hendricks et al. 1978) supplemented with 20\% heatinactivated foetal bovine serum, following the culture of liver and spleen tissue from a sloth, Choloepus hoffmanni and a squirrel, Sciurus granatensis, caught in forest on the Pacific coast (Hashiguchi 1987, Hashiguchi et al. 1985). No isolates were made from cultures of the skin.

On biological, biochemical, serological and molecular criteria the two isolates were indistinguishable, and differed from all known neotropical species of Leishmania. The parasite was considered to represent a new species of this genus and received the name of $L$. equatorensis "...of the $L$. braziliensis complex..." (Grimaldi et al. 1992). In the numerical zymotaxonomy studies of Cupolillo et al. (1994), however, the two isolates were classified as members of the subgenus Leishmania (but unrelated to the mexicana complex). Paucity of isolates makes it impossible to say which animals are the major hosts of this parasite, and the examination of many more strains is clearly indicated to establish its true identity: the vector remains unknown. Undoubted Leishmania species known from sloths include $L$. (V.) panamensis, $L$. (V.) guyanensis and $L$. (V.) shawi, all of which are important causes of human leishmaniasis (Lainson \& Shaw 1987, Shaw et al. 1991). It remains to be seen if the parasite from Ecuador occurs in other parts of South America and if it is capable of infecting man.

\section{LEISHMANIA HERRERI}

In Costa Rica, Zeledón et al. (1975) found numerous sloths (Choloepus hoffmanni and Bradypus griseus) to be infected with Leishmania, probably $L$. (L.) panamensis. The identification of isolates was complicated, however, by frequent concomitant infection with Endotrypanum (an intraerythrocytic kinetoplastid, peculiar to sloths), which also grows as promastigotes in both sandflies and blood-agar cultures. One isolation, however, was considered to be a pure culture of Leishmania and the inoculation of culture forms into hamster cell tissue-cultures produced intracellular amastigotes. On the other hand, the inoculation of the same culture forms into the skin of hamsters produced only a few sphaeromastigotes (for definition, see Hoare \& Wallace 1966), in the absence of any visible lesion (Zeledón et al. 1979). The organism was named Leishmania herreri Zeledón, Ponce \& Murillo 1979.

In the paper describing the parasite, the authors cited a personal communication from Dr ML Chance, who examined the parasite's biochemistry and concluded that it was "....totally different from other known haemoflagellates". Lainson and Shaw (1987) suggested that this and the uncharacteristic production of sphaeromastigotes in hamster skin did not suggest " $L$. herreri" to be a member of the genus Leishmania, a conclusion supported by recent comparative studies on the molecular biology of three isolates of the flagellate which indicated that the parasite is "....more closely related to Endotrypanum.... than to Leishmania" (Noyes et al. 1996)

\section{CONCLUSIONS}

Hypotheses regarding the origin of the parasitic Kinetoplastida, the family Trypanosomatidae and the genus Leishmania have been discussed in detail elsewhere (Lainson \& Shaw 1987).

The concensus of opinion is that the trypanosomatids derive from monogenetic intestinal flagellates of invertebrates, which subsequently adapted to spend a part of their life-cycle in vertebrates. If this is so, it is the phlebotomine sandfly that is to be regarded as the primitive or primary host of Leishmania species, and not the vertebrate hosts which merely act as reservoirs of infection for the sandfly. The existence of a sexual phase of development in the insect host would strongly support this hypothesis. Although Lanotte and Rioux (1990) have shown that the promastigotes of in vitro cultures of some species of Leishmania apparently undergo a form of conjugation, possibly 
with the exchange of nuclear material, and other data suggests the formation of hybrids of Leishmania species in nature (Darce et al.1991, BonfanteGarrido et al.1992, Belli et al.1994, Dujardin et al. 1995), a distinct sexual stage has not yet been shown to be an integral part of the life-cycle of Leishmania.

Over the past 30 years, improving methods in the detection, isolation and identification of Leishmania has clearly indicated a multiplicity of species of this parasite. At present, 30 have been named, with 10 in the Old World and 20 in the New World. Speciation appears, then, to have been most marked in the neotropics, and this is most probably due to the much greater range of sandfly species in the Americas.

The degree of specificity of Leishmania species in their sandfly hosts in nature has been poorly studied, and it is unwise to draw conclusions from laboratory experiments in which unnaturally large numbers of amastigotes, or even promastigotes from in vitro cultures, have been fed to laboratorybred sandflies. The natural resistance of a nonvector may be overpowered by the sheer weight of numbers of parasites ingested. Ecological observations, however, leave us with little doubt that there are natural barriers which limit the life-cycle of most leishmanial parasites to specific sandfly vectors. Thus, to date, Lu. longipalpis is the only proven vector of $L$. (L.) chagasi, the causative agent of American visceral leishmaniasis; $L u$. olmeca olmeca transmits $L$. (L.) mexicana among rodents in Central America; Lu. flaviscutellata is the proven vector of $L$. (L.) amazonensis in Amazonian Brazil; Ps. wellcomei is the sandfly host of $L$. (V.) braziliensis sensu lato in primary forest in the highlands of Pará, north Brazil; and $L u$. umbratilis is the major sandfly host of $L$. (V.) guyanensis throughout the geographic range of this parasite. On the other hand, as some sandflies feed on a variety of mammalian hosts in nature, the Leishmania species harboured by a given sandfly species may sometimes be isolated from a number of different animals sharing the same habitat. Notable examples are $L$. (L.) amazonensis in a wide variety of largely terrestrial forest rodents and marsupials; L. (V.) guyanensis in arboreal sloths, anteaters and opossums; and $L$. (V.) shawi in sloths, monkeys and procyonids which, again, spend much of their time in the forest canopy.

Just how many species of Leishmania exist in the neotropics is anybody's guess, and we will gain some idea of this only when sufficient numbers of all the recorded sandfly species have been examined and their leshmanial parasites isolated and identified. A truly gigantic task, considering that nearly
400 species and subspecies of these insects have been identified in South and Central America, the West Indies and Mexico (Young \& Duncan 1994). The Amazon Region has already provided us with almost a half of the recognized species of neotropical leishmanias and in a recent publicaton (Lainson et al. 1994) we have listed a number of Amazonian mammals and sandflies found infected with Leishmania or promastigotes of doubtful taxonomy, suggesting that this great forest will furnish us with many more!

\section{REFERENCES}

Anon 1957. The twenty-ninth annual report of the work and operation of the Gorgas Memorial Laboratory, covering the fiscal year ended June 30, 1956. United States Government Printing Office, Washington.

Anon 1959. Thirty-first annual report of the work and operation of the Gorgas Memorial Laboratory, covering the fiscal year ended June 30, 1958. United States Government Printing Office, Washington.

Barreto AC, Peterson NE, Lago E, Rosa AC, Braga RSM, Cuba Cuba AC, Vexenat JA, Marsden PD 1985. Leishmania mexicana in Proechimys iheringi denigratus Moojen (Rodentia: Echimyidae) in region endemic for American cutaneous leishmaniasis. Rev Soc Bras Med Trop 18: 243-246.

Belli AA, Miles MA, Kelly JM 1994. A putative Leishmania panamensis/Leishmania braziliensis hybrid is a causative agent of human cutaneous leishmaniasis in Nicaragua. Parasitol 109: 435-442.

Bonfante-Garrido R, Meléndez E, Barroeta S, de Alejos MAM, Momen H, Cupolillo E, McMahon-Pratt D, Grimaldi G 1992. Cutaneous leishmaniasis in Western Venezuela caused by infection with Leishmania venezuelensis and L. braziliensis variants. Trans $R$ Soc Trop Med Hyg 86: 141-148.

Christensen HA, Herrer A, Telford SR 1972. Enzootic cutaneous leishmaniasis in eastern Panama. II. Entomological investigations. Ann Trop Med Parasitol 66: 55-66.

Croft SL, Schnur LF, Chance ML 1978. The morphological, biochemical and serological characterization of strains of Leishmania hertigi from Panama and Brazil and their differentiation. Ann Trop Med Parasitol 72: 93-94.

Cupolillo E, Grimaldi G, Momen H 1994. A general classification of New World Leishmania using numerical zymotaxonomy. Am J Trop Med Hyg 50: 296-311.

Darce M, Moran J, Palacios X, Belli A, Gomez-Urcuyo F, Zamora D, Valle S, Gantier JC, Momen H, Grimaldi G 1991. Etiology of human cutaneous leishmaniasis in Nicaragua. Trans $R$ Soc Trop Med Hyg 85: 58-59.

Deane LM, Silva JE, Figueiredo PZ 1974. Leishmaniae in the viscera of porcupines from the State of Piauí Brazil. Rev Inst Med Trop São Paulo 16: 68-69.

Disney RHL 1966. A trap for phlebotomine sandflies attracted to rats. Bull Ent Res 56: 445-451. 
Dujardin JC, Bañuls AL, Llanos-Cuentas A, Alvarez E, DeDoncker S, Jacquet D, Le Ray D, Arevalo J, Tibayrenc M 1995. Putative Leishmania hybrids in Eastern Andean valley of Huanuco, Peru. Acta Trop 59: 293-307.

Forattini OP 1960. Sobre os reservatórios naturais da leishmaniose tegumentar americana. Rev Inst Med Trop São Paulo 2: 195-203.

Grimaldi G, Tesh RB, McMahon-Pratt D 1989. A review of the geographic distribution and epidemiology of leishmaniasis in the New World. Am J Trop Med Hyg 41: 687-725.

Grimaldi G, Kreutzer RD, Hashiguchi Y, Gomez EA, Mimory T, Tesh RB 1992. Description of Leishmania equatorensis sp.n. (Kinetoplastida: Trypanosomatidae), a new parasite infecting arboreal mammals in Ecuador. Mem Inst Oswaldo Cruz 87: 221-228.

Hashiguchi Y 1987. Studies on New World leishmaniasis and its transmission, with particular reference to Ecuador. Res Rep Ser No 1. Kochi, Japan: Kyowa Press.

Hashiguchi Y, Gomez EA, de Coronel VV, Mimori T, Kabata M 1985. Leishmania isolated from wild mammals caught in endemic areas of leishmaniasis in Ecuador. Trans $R$ Soc Trop Med Hyg 79: 120-121.

Hendricks LD, Wood DE, Hadjuk ME 1978. Haemoflagellates: commercially available liquid media for rapid cultivation. Parasitology 74: 309316.

Herrer A 1971. Leishmania hertigi sp.n. from the tropical porcupine, Coendou rothschildi Thomas. J Parasitol 57: 626-629.

Hoare CA, Wallace FG 1966. Developmental stages of trypanosomatid flagellates: a new terminology. Nature, London, 212: 1385-1386.

Kreutzer RD, Corredor A, Grimaldi G, Grogl M, Rowton ED, Young DG, Morales A, McMahon-Pratt D, Guzman H, Tesh RB 1991. Characterization of Leishmania colombiensis sp.n. (Kinetoplastida: Trypanosomatidae), a new parasite infecting humans, animals and phlebotomine sandflies in Colombia and Panama. Amer J Trop Med Hyg 44: 662675.

Lainson R 1982a. Leishmanial parasites of mammals in relation to human disease, p.137-179. In MA Edwards \& U McDonnell (eds) Animal Disease in Relation to Animal Conservation. Symposia of the Zoological Society of London.

Lainson R 1982b. Leishmaniasis, p. 41-103. In JH Steele CRC Handbook Series in Zoonoses, Section $C$ : Parasitic zoonoses Vol. 1. CRC Press Inc., Boca Raton, Florida.

Lainson R 1983. The American leishmaniases: some observations on their ecology and epidemiology. Trans $R$ Soc Trop Med Hyg 77: 569-596.

Lainson R, Shaw JJ 1977. Leishmanias of neotropical porcupines: Leishmania hertigi deanei nov. subsp. Acta Amazônica 7: 51-57.

Lainson R, Shaw JJ 1979. The role of animals in the epidemiology of South American leishmaniasis, p. 1-116. In WHR Lumsden \& DA Evans (eds) Biol- ogy of the Kinetoplastida, Vol. 2. Academic Press, London.

Lainson R, Shaw JJ 1987. Evolution, classification and geographical distribution, p. 1-120 In W Peters \& R Killick-Kendrick (eds) The leishmaniases in biology and medicine, Vol. 1. Biology and Epidemiology. Academic Press, London.

Lainson R, Strangways-Dixon J 1962. Dermal leishmaniasis in British Honduras: some host-reservoirs of Leishmania braziliensis mexicana. A preliminary note. Brit Med J 1: 1596-1598.

Lainson R, Strangways-Dixon J 1964. The epidemiology of dermal leishmaniasis in British Honduras. Part II. Reservoir-hosts of Leishmania mexicana among the forest rodents. Trans $R$ Soc Trop Med Hyg 58: 136-153.

Lainson R, Shaw JJ, Ward RD, Ready PD, Naiff RD 1979. Leishmaniasis in Brazil. XIII. Isolation of Leishmania from armadillos (Dasypus novemcintus), and observations on the epidemiology of cutaneous leishmaniasis in north Pará State. Trans $R$ Soc Trop Med Hyg 73: 239-242.

Lainson R, Shaw JJ, Silveira FT, Braga RR, Ishikawa EAY 1990. Cutaneous leishmaniasis of man due to Leishmania (Viannia) naiffi Lainson \& Shaw, 1989. Ann Parasitol Hum Comp 65: 282-284.

Lainson R, Shaw JJ, Silveira FT, de Souza AAA, Braga RR, Ishikawa EAY 1994. The dermal leishmaniases of Brazil, with special reference to the eco-epidemiology of the disease in Amazonia. Mem Inst Oswaldo Cruz 89: 435-443.

Lanotte G, Rioux J-A 1990. Fusion cellulaire chez les Leishmania (Kinetoplastida: Trypanosomatidae). C $R$ Acad Sci Paris 10: 285-288.

Luz E, Giovannoni M, Borba AM 1967. Infecção de Lutzomyia monticola por Leishmania enriettii. An Fac Med Univ Fed Paraná 9-10: 121-128.

Machado MI, Milder RV, Pacheco RS, Braga RR, Lainson R 1994. Naturally acquired infections with Leishmania enrietti Muniz and Medina 1948 in guinea-pigs from São Paulo, Brazil. Parasitology 109: 135-138.

Medina HSG 1946. Estudos sobre leishmaniose. I. Primeiros casos de leishmaniose espontânea observados em cobaios. Arq Biol Tecnol (Curitiba) 1: 39-74.

Miles MA, Póvoa MM, de Souza AA, Lainson R, Shaw JJ 1980. Some methods for the enzymic characterization of Latin-American Leishmania with particular reference to Leishmania mexicana amazonensis and subspecies of Leishmania hertigi. Trans $R$ Soc Trop Med Hyg 74: 243-252.

Muniz J, Medina HSG 1948. Leishmaniose tegumentar do cobaio (Leishmania enriettii n.sp). Hospital (Rio de Janeiro) 33: 7-25.

Naiff RD, Freitas RA, Arias JR, Barrett TV 1989. Aspectos epidemiológicos de uma Leishmania de tatus (Dasypus novemcinctus). Prog Resum XI Congr Bras Parasitol, p. 24.

Noyes HA, Camps AP, Chance ML 1996. Leishmania herreri (Kinetoplastida; Trypanosomatidae) is more closely related to Endotrypanum (Kinetoplastida; 
Trypanosomatidae) than to Leishmania. Mol Biochem Parasitol 80: 119-123.

Shaw JJ, Lainson R 1987. Ecology and Epidemiology: New World, p. 291-363. In W Peters \& R KillickKendrick (eds) The leishmaniases in biology and medicine, Vol. 1, Biology and Epidemiology. Academic Press, London.

Shaw JJ, Ishikawa EAY, Lainson R, Braga RR, Silveira FT 1991. Cutaneous leishmaniasis of man due to Leishmania (Viannia) shawi Lainson, de Souza, Póvoa, Ishikawa \& Silveira, in Pará State, Brazil. Ann Parasitol Hum Comp 66: 243-246.

Yoshida ELA, Silva R, Cortez LS, Corrêa FMA 1979. Encontro de espécie do gênero Leishmania em Didelphis marsupialis aurita no Estado de São Paulo, Brasil. Rev Inst Med trop São Paulo 21: 110-113.

Yoshida ELA, Corrêa FMA, Pacheco RS, Momen H, Grimaldi G 1985. Leishmania mexicana in Didelphis marsupialis aurita in São Paulo State, Brazil.
Rev Inst Med Trop São Paulo 27: 172.

Yoshida ELA, Cuba Cuba CA, Pacheco RS, Cupolillo E, Tavares CC, Machado GMC, Momen H, Grimaldi G 1993. Description of Leishmania (Leishmania) forattinii sp.n., a new parasite infecting opossums and rodents in Brazil. Mem Inst Oswaldo Cruz 88: 397-406.

Young DG, Duncan MA 1994. Guide to the identification and geographic distribution of Lutzomyia sand flies in Mexico, the West Indies, Central and South America (Diptera: Psychodidae). Mem Amer Ent Inst No 54. Associated Publishers, American Entomological Institute, $881 \mathrm{pp}$.

Zelodón R, Ponce C, Ponce E 1975. The isolation of Leishmania braziliensis from sloths in Costa Rica. Am J Trop Med Hyg 24: 706-707.

Zelodón R, Ponce C, Murillo J 1979. Leishmania herreri sp.n. from sloths and sandflies of Costa Rica. $J$ Parasitol 65: 275-279. 
388 Enigmatic Species of Leishmania - Ralph Lainson 